\title{
MÉTODO DE OBTENÇÃO DE MATÉRIA SECA E COMPOSIÇÃO QUÍMICA DE VOLUMOSOS
}

\section{DRY MATTER OBTAINIMENT METHOD AND CHEMICAL COMPOSITION OF ROUGHAGES}

\author{
Antonio Vinicius lank Bueno ${ }^{1 *}$ \\ Cloves Cabreira Jobim ${ }^{1}$ \\ Matheus Gonçalves Ribeiro' \\ Janaina Prieto de Oliveira ${ }^{1}$ \\ 1 Universidade Estadual de Maringá, Maringá, PR, Brasil. \\ *Autor para correspondência - vinicius_bueno602@hotmail.com
}

\section{Resumo}

Objetivou-se avaliar a influência do método de secagem sobre a composição nutricional de diferentes volumosos. Foram utilizadas quatro gramíneas (Urochloa brizantha cv. Marandu, Urochloa brizantha cv. MG4, Cynodon dactylon cv. Coastcross e Panicum maximum cv. Áries), uma leguminosa forrageira, o estilosante (Stylosanthes cv. Campo Grande) e duas silagens (Zea mays e Triticum aestivum cv. BRS Umbu). Os métodos de secagem se basearam no uso da estufa de ventilação forçada e de forno de micro-ondas. $\mathrm{O}$ delineamento estatístico utilizado foi um arranjo fatorial 2 × 8 ( 2 métodos de secagem e 8 volumosos) com 4 repetições. $O$ método de secagem não influenciou o conteúdo de matéria seca das forragens. A secagem em forno micro-ondas elevou os teores de fibra em detergente neutro nos volumosos avaliados. Houve interação entre o método de secagem e tipo de forragem avaliada, com relação à proteína bruta (estilosante), extrato etéreo (MG4, estilosante e Áries) e nitrogênio insolúvel em detergente neutro (Coastcross, MG4, Marandu e estilosante). O forno de micro-ondas pode ser utilizado como instrumento para obtenção da matéria seca em alimentos volumosos, porém, a técnica pode afetar a composição da forragem avaliada.

Palavras-chaves: estufa; micro-ondas; parede celular; proteína bruta; extrato etéreo.

\begin{abstract}
It was aimed determinate the influence of drying methods on nutritional composition of different roughages. The experimental material were four grass species (Urochloa brizantha cv. Marandu, Urochloa brizantha cv. MG4, Cynodon dactylon cv. Coastcross e Panicum maximum cv. Áries), one forage legume (Stylosanthes cv. Campo Grande) and two silages (Zea mays e Triticum aestivum cv. BRS Umbu). The drying methods were based on use of forced air oven or microwave oven. The experimental design were a 2 × 8 factorial arrangement ( 2 drying methods and 8 roughages) with 4 repetitions. There was no effect of drying method on roughages dry matter content. Microwave oven drying increased neutral detergent fiber. There was an interaction between drying method and evaluated
\end{abstract}


roughage. Increased contents of crude protein (estilosante), neutral detergent insoluble nitrogen (Coastcross, MG4, Marandu e estilosante) and ether extract (MG4, estilosante e Áries) were observed when roughages were dried using microwave oven. The microwave oven usage is an alternative to obtain the dry matter content of roughages; however this technic may affect the sample composition.

Keywords: forced air oven; microwave oven; cell wall; crude protein; ether extract.

Recebido em: 9 de janeiro de 2017

Aceito em: 11 de setembro de 2017

\section{Introdução}

A determinação do conteúdo de umidade de alimentos é um dos procedimentos rotineiros mais realizados no que concerne à produção de alimentos volumosos para ruminantes. A matéria seca (MS) tem sido utilizada como importante parâmetro para expressar a produção de forrageiras, podendo apresentar variações conforme a espécie, maturidade da planta, manejo da cultura, condições ambientais e estação do ano ${ }^{(1)}$.

A secagem do material vegetal é necessária para evitar alterações químicas e degradação dos tecidos durante o período de armazenamento prévio às posteriores análises. Além disso, é requerida para estimar as quantidades de nutrientes presentes no alimento, os quais são expressos na base seca por ser uma medida padronizada ${ }^{(2)}$.

A metodologia comumente utilizada faz uso de estufa de ventilação forçada, sendo esta descrita por vários autores $^{(2,3)}$. Porém, muitas vezes não é possível dispor de tal equipamento, o que ocorre com frequência a campo. Além disso, em muitas situações necessita-se obter os valores de MS para tomada de decisão imediata. Como exemplo, cita-se corte de forrageiras para ensilagem, fenação ou mesmo para tomadas de decisão no manejo de pastos.

Desta forma, alguns autores descrevem o uso do forno de micro-ondas como alternativa para secagem de materiais úmidos, sendo esta técnica descrita desde a década de 1950 por vários pesquisadores como uma forma rápida para a determinação da MS em programas de melhoramento de plantas forrageiras ${ }^{(4,5)}$. Atualmente, esta técnica vem sendo empregada por vários autores ${ }^{(6-9)}$ para determinação da MS e obtenção das mais diversas variáveis com relação à composição química de vários alimentos, desde volumosos até grãos.

Contudo, por este método ser baseado no aquecimento do material em altas temperaturas, embora por pequeno período de tempo, alterações podem ocorrer na composição química do alimento, como relatado por Natsir et al. ${ }^{(10)}$. Estes autores observaram que o uso de radiação de micro-ondas foi capaz de alterar a composição química da palha de cevada. Tal fato pode gerar resultados equivocados e induzir a interpretações errôneas com relação à verdadeira composição nutricional do alimento. Desta forma, o presente trabalho tem como objetivo comparar o processo de secagem, em forno de micro-ondas e em estufa de ventilação de ar forçada, em relação aos efeitos na composição química de diferentes alimentos volumosos. 


\section{Material e Métodos}

O experimento foi conduzido na Fazenda Experimental de Iguatemi-FEI, localizada na latitude de $23^{\circ} 25^{\prime} \mathrm{S} ; 5^{\circ} 57^{\prime} \mathrm{O}$, e com altitude de 550 metros. As análises químicas foram realizadas no Laboratório de Análises de Alimentos e Nutrição Animal - LANA, no Departamento de Zootecnia, pertencente à Universidade Estadual de Maringá. Foram colhidas amostras de cinco espécies forrageiras, no campo agrostológico da Universidade Estadual de Maringá, sendo quatro gramíneas (Urochloa brizantha cv. Marandu, Urochloa brizantha cv. MG4, Cynodon dactylon cv. Coastcross e Panicum maximum cv. Áries), uma leguminosa forrageira, o estilosante (Stylosanthes cv. Campo Grande) e duas silagens, sendo a de milho (Zea mays) e trigo (Triticum aestivum cv. BRS Umbu).

As amostras das silagens foram acondicionadas em sacos plásticos identificados e congeladas para posteriores análises juntamente com as amostras de forragem verde. Os tratamentos consistiram na determinação do teor de MS pelo método convencional em estufa com ventilação de ar forçada (EST), segundo Silva e Queiroz ${ }^{(3)}$ e na obtenção do teor de MS utilizando forno de micro-ondas (FMO), segundo metodologia descrita por Lacerda et al. ${ }^{(4)}$.

Para cada amostra, foram utilizados $0,5 \mathrm{~kg}$ de forragem fresca para secagem em estufa de ventilação de ar forçada $\left(55^{\circ} \mathrm{C}\right.$ ) por até 72 horas e em FMO (potência de 900 watts). O FMO tinha capacidade para 30 litros, contendo no interior um copo com $150 \mathrm{~mL}$ de água a fim de umedecer o ambiente e evitar a queima das amostras. O processo de secagem por FMO foi realizado através de ciclos com diferentes durações, sendo a amostra mantida primeiramente em aquecimento durante 3 ciclos de 5 minutos, passando-se para um ciclo de 3 minutos e logo após um ciclo de 2 minutos. Após este último, seguiram-se ciclos de um minuto, com pesagem do material até que este atingisse peso constante.

As amostras (quatro para cada forragem) avaliadas foram pesadas antes e depois da secagem, em balança de precisão, sendo descontado o recipiente de armazenagem, utilizando a seguinte equação para determinar o teor de matéria seca: MS $(\%)=[(\mathrm{C}-\mathrm{A}) \times 100] /(\mathrm{B}-\mathrm{A})$, sendo: C peso da amostra seca; B peso da amostra fresca; e A peso do recipiente utilizado. Para posterior transformação para base $g$ $\mathrm{kg}^{-1}$ de matéria natural (MN), multiplicou-se o valor obtido por 10.

Após a obtenção da MS, as amostras foram moídas em moinho tipo Willey a $1 \mathrm{~mm}$, sendo determinadas as variáveis de, matéria seca a $105^{\circ} \mathrm{C}$, extrato etéreo (EE), matéria mineral (MM) conforme descrito por Detmann et al. ${ }^{(2)}$, proteína bruta (PB) segundo AOAC ${ }^{(11)}$ (método 990.03), fibra em detergente ácido (FDA) e fibra em detergente neutro (FDN), segundo Van Soest et al. ${ }^{(12)}$. O nitrogênio insolúvel em detergente ácido (NIDA) e nitrogênio insolúvel em detergente neutro (NIDN) foram determinados sequencialmente nos resíduos após análise de FDN e FDA.

O delineamento experimental utilizado foi um arranjo fatorial $2 \times 8$ (2 métodos de secagem e 8 espécies forrageiras), com 4 repetições. Os dados coletados para cada variável foram submetidos à análise de variância, por intermédio do procedimento GLM programa estatístico $\mathrm{SAS}^{(13)}$, e as diferenças entre as médias comparadas pelo teste Tukey ao nível de significância de 5\%. 


\section{Resultados e Discussão}

A metodologia de secagem não influenciou os teores de MS (Figura 1). Contudo, o FMO age irradiando ondas eletromagnéticas, que, ao atingirem as moléculas do alimento, fazem estas vibrarem em várias direções. Durante esse processo de agitação molecular, a energia gerada é dissipada na forma de calor aquecendo o material ${ }^{(14)}$, o que leva à evaporação da água presente na forragem alterando o teor de MS da planta. Porém, esse processo se dá de forma muito rápida quando comparado com a estufa de ar forçado (onde o material permanece a $55^{\circ} \mathrm{C}$ por até 72 horas) podendo haver excessiva retirada de água de dentro das células ${ }^{(2-4)}$.

Calixto Jr et al. ${ }^{(7)}$, ao avaliarem a taxa de secagem do feno de grama-estrela (Cynodon nlemfuensis), observaram que o uso do FMO resultou em teores de MS mais elevados em relação a EST, tanto para a planta inteira quanto para as frações folha e colmo. Desta forma, tal comportamento fez com que as curvas de desidratação avaliadas utilizando o FMO fossem mais acentuadas, contudo, os autores concluem que o uso do FMO se mostra como uma alternativa ao uso da EST, pois possui eficiência semelhante.

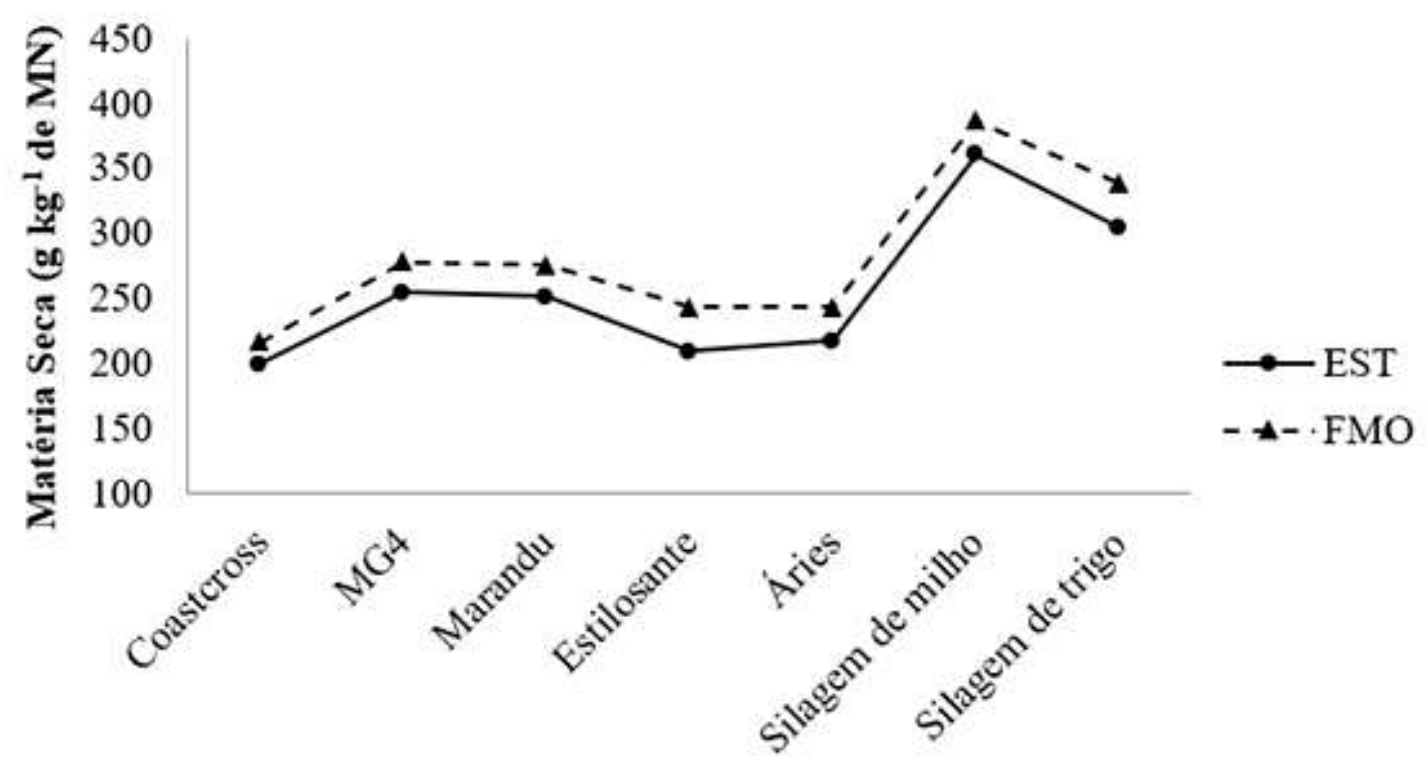

Figura 1. Efeito do método de secagem sobre os teores de matéria seca de diferentes forragens (base $\mathrm{g} \mathrm{kg}^{-1}$ de matéria natural).

Como esperado, por se tratarem de materiais totalmente distintos, diferenças foram observadas com relação à composição química das forragens (Tabela 1). $\mathrm{O}$ método de secagem não influenciou os valores encontrados para MM, FDA e NIDA. Contudo, notou-se que o uso do FMO foi capaz de elevar o teor de FDN das forragens avaliadas. Para as variáveis PB, EE e NIDN, observou-se interação entre o método de secagem e tipo de volumoso avaliado. 
Tabela 1. Composição nutricional de forragens em função do método de secagem

\begin{tabular}{cccccccc}
\hline & \multicolumn{7}{c}{$\mathbf{g ~ k g}^{-1} \mathbf{d e}$ Matéria Seca } \\
\cline { 2 - 8 } & MM & PB & EE & FDN & FDA & NIDN & NIDA \\
\hline Forragem (F) & & & & & & & \\
CC & $78^{\mathrm{a}}$ & $84,4^{\mathrm{c}}$ & $18,7^{\mathrm{abc}}$ & $656,4^{\mathrm{ab}}$ & $365,3^{\mathrm{bc}}$ & $29,9^{\mathrm{b}}$ & $11,8^{\mathrm{c}}$ \\
MG4 & $72,9^{\mathrm{a}}$ & $71,7^{\mathrm{d}}$ & $16,4^{\mathrm{abc}}$ & $679^{\mathrm{ab}}$ & $387^{\mathrm{b}}$ & $27,2^{\mathrm{b}}$ & $13,3^{\mathrm{c}}$ \\
MRD & $67,6^{\mathrm{ab}}$ & $70,8^{\mathrm{d}}$ & $13,9^{\mathrm{c}}$ & $709,6^{\mathrm{a}}$ & $405,6^{\mathrm{ab}}$ & $34,6^{\mathrm{b}}$ & $14,6^{\mathrm{b}}$ \\
EST & $55,4^{\mathrm{b}}$ & $118^{\mathrm{a}}$ & $15,3^{\mathrm{bc}}$ & $603,1^{\mathrm{b}}$ & $464,8^{\mathrm{a}}$ & $61,9^{\mathrm{a}}$ & $22,1^{\mathrm{a}}$ \\
AR & $79,9^{\mathrm{a}}$ & $88,8^{\mathrm{bc}}$ & $14,3^{\mathrm{c}}$ & $708,5^{\mathrm{a}}$ & $417,5^{\mathrm{ab}}$ & $66,6^{\mathrm{a}}$ & $19,7^{\mathrm{b} b}$ \\
SM & $39,5^{\mathrm{c}}$ & $98^{\mathrm{b}}$ & $21,3^{\mathrm{a}}$ & $505,1^{\mathrm{c}}$ & $321,3^{\mathrm{cd}}$ & $15,2^{\mathrm{c}}$ & $9,8^{\mathrm{c}}$ \\
ST & $36,4^{\mathrm{c}}$ & $59,1^{\mathrm{e}}$ & $19,8^{\mathrm{ab}}$ & $480,3^{\mathrm{c}}$ & $294,6^{\mathrm{d}}$ & $29,5^{\mathrm{b}}$ & $18,5^{\mathrm{ab}}$ \\
Método de & & & & & & & \\
Secagem (S) & & & & & & & \\
EST & 60,4 & 81,5 & 15,3 & 604,6 & 378,8 & 30,3 & 15 \\
FMO & 61,6 & 87,3 & 18,9 & 632,3 & 380,6 & 44,1 & 16,3 \\
EPM & 0,24 & 0,27 & 0,06 & 1,29 & 0,87 & 0,27 & 0,08 \\
P-Valor & & & & & & & \\
S & NS & $* *$ & $* *$ & $*$ & NS & $* * *$ & NS \\
F & $* * *$ & $* * *$ & $* * *$ & $* * *$ & $* * *$ & $* * *$ & $* * *$ \\
F×S & NS & $* *$ & $* *$ & NS & NS & $* *$ & NS \\
\hline
\end{tabular}

zkcdìédias na mesma coluna diferem entre si pelo teste Tukey $\left({ }^{*} \mathrm{P}<0,05 ;{ }^{* *} \mathrm{P}<0,01 ;{ }^{*} * \mathrm{P}<0,001\right)$. EPM=Erro padrão da média. NS=Não significativo. EST=Estufa de ventilação forçada. $\mathrm{FMO}=\mathrm{Forno}$ de micro-ondas. ${ }^{A}$ Cynodion dactylon cv. Coastcross. ${ }^{2}$ Urochloa brizantha cv. MG4. ${ }^{3}$ Urochloa brizantha cv. Marandu. ${ }^{4}$ Stylosanthes cv. Campo Grande. ${ }^{5}$ Panicum maximum cv Áries. ${ }^{6}$ Silagem de milho (Zea mays). ${ }^{7}$ Silagem de trigo (Trificum aestivum $\mathrm{cv}$. BRS Umbu).

Sabe-se que a elevação de temperatura pode alterar negativamente a composição da parede celular, elevando o conteúdo de fibra da forragem, uma vez que esta é mesurada através de métodos gravimétricos $^{(2,12)}$. Contudo, a fração fibrosa do volumoso é inerte, ou seja, não há perda ou acúmulo de parede celular durante a secagem do material, diferentemente do que ocorre com outros compostos voláteis como ácidos orgânicos, compostos nitrogenados, como a amônia, ou carboidratos solúveis, caso a secagem seja lenta.

Sendo assim, quaisquer alterações para esta fração do alimento podem ser derivadas da perda de compostos solúveis, como supracitado ou, então, provenientes de reações entre compostos carbônicos (como os presentes na parede celular) com minerais ou grupamentos amino, vindos da fração nitrogenada solúvel de proteína danificada pelo calor de maneira não enzimática (reação de Maillard), a qual é catalisada pelo aumento de temperatura no alimento ${ }^{(15,16)}$, corroborando com a elevação no conteúdo de NIDN observado para Coastcross, MG4, Marandu e estilosante (Tabela 2). Pelletier et al. ${ }^{(17)}$ também relataram elevação dos teores de NIDN em amostras de forrageiras após secagem com uso de FMO.

Elevações no conteúdo de PB e EE podem ocorrer caso haja uma redução na concentração de 
compostos de maior solubilidade devido ao aquecimento do material, por meio de efeito de diluição $^{(18,19)}$, como relatado para fração fibrosa. Com relação à PB, Natsir et al. ${ }^{(10)}$ e Lacerda et al. $^{(4)}$ observaram comportamento semelhante ao encontrado neste estudo para o estilosante neste estudo, em que o uso de FMO também elevou a concentração de PB para a silagem de milho e milho grão, respectivamente. Contudo, Pereira da Silva et al. ${ }^{(6)}$ não observaram quaisquer alterações no conteúdo de nitrogênio das folhas do capim braquiária (Urochloa sp.), cana-de-açúcar (Saccharum officinarum) ou goiabeira (Psidum guajuva L.), assim como para as demais forragens avaliadas neste estudo. Resultados semelhantes foram descritos por Marcante et al. ${ }^{(20)}$.

Tabela 2. Desdobramento do da interação entre método de obtenção de matéria seca e composição química de forragens (base $\mathrm{g} \mathrm{kg}^{-1}$ de MS)

\begin{tabular}{|c|c|c|c|c|c|c|c|c|}
\hline \multirow{2}{*}{$\begin{array}{l}\text { Método de } \\
\text { Secagem }\end{array}$} & \multicolumn{7}{|c|}{ Forragens } & \multirow{2}{*}{ EPM } \\
\hline & ${ }^{1} \mathrm{CC}$ & ${ }^{2} \mathrm{MG} 4$ & ${ }^{3}$ MRD & ${ }^{4}$ EST & ${ }^{5} \mathrm{AR}$ & ${ }^{6} \mathrm{SM}$ & ${ }^{7} \mathrm{ST}$ & \\
\hline \multicolumn{9}{|c|}{ PB } \\
\hline EST & 82,6 & 68,3 & 75,3 & $101,9^{\mathrm{a}}$ & 89,8 & 93,8 & 5,98 & 0,29 \\
\hline FMO & 86,1 & 75,0 & 66,4 & $132,3^{b}$ & 90,1 & 102,6 & 5,84 & 0,45 \\
\hline \multicolumn{9}{|c|}{ NIDN } \\
\hline EST & $19,2^{b}$ & $22,3^{b}$ & $25^{b}$ & $46,9^{b}$ & 38,21 & 15,4 & 29,4 & 0,041 \\
\hline FMO & $40,5^{\mathrm{a}}$ & $32,1^{2}$ & $43,4^{a}$ & $77,7^{\mathbf{a}}$ & 42,05 & 14,9 & 29,6 & 0,043 \\
\hline \multicolumn{9}{|c|}{$\mathrm{EE}$} \\
\hline EST & 20,5 & $10,5^{\mathrm{a}}$ & 14,1 & $12,9^{2}$ & $10,2^{\mathrm{a}}$ & 20,4 & 18,4 & 0,13 \\
\hline FMO & 17 & $22,4^{b}$ & 13,7 & $17,6^{b}$ & $18,4^{b}$ & 22,3 & 21,2 & 0,08 \\
\hline
\end{tabular}

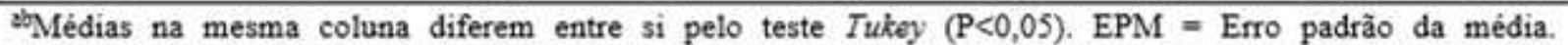
EST=Estufa de ventilaçăo forçada. FMO=Forno de micro-ondas. ${ }^{2}$ Cynodon dactylon cv. Coastcross. ${ }^{2}$ Urochloa brizantha cv. MG4. ${ }^{3}$ Urochloa brizantha $\mathrm{cv}$. Marandu. ${ }^{4}$ Stylosanthes $\mathrm{cv}$. Campo Grande. ${ }^{5}$ Panicum maximum $\mathrm{cv}$ Aries. ${ }^{6}$ Silagem de milho (Zea mays). ${ }^{7}$ Silagem de trigo (Triticum aestivum $\mathrm{cv}$. BRS Umbu).

\section{Conclusões}

O forno de micro-ondas pode ser utilizado como ferramenta para obtenção da matéria seca em alimentos volumosos, podendo substituir a estufa. Contudo, é importante ressaltar que alterações na composição do alimento podem ocorrer, uma vez que pode haver maior retirada de água do alimento, além desta tecnologia poder elevar a concentração de fibra em detergente neutro, do nitrogênio complexado à parede celular, proteína bruta e extrato etéreo. É necessária a condução de estudos posteriores avaliando o impacto de tal técnica sobre a qualidade de carboidratos solúveis e fracionamento proteico. 


\section{Referências}

1. Crespo RJ, Castaño JA, Capurro JA. Secado de forraje con el horno microondas: efecto sobre el análisis de calidad. Agricultura Técnica [Internet]. 2007 Jun [citado 2016 Nov 18]; 67(2):210-218. http://dx.doi.org/10.4067/S0365-28072007000200013. Espanhol.

2. Detmann E, Souza MA, Valadares Filho SC. Métodos para Análise De Alimentos. Visconde do Rio Branco: Universidade Federal de Viçosa; 2012. Português.

3. Silva DJ, Queiroz AC. Análise de alimentos: Métodos Químicos e Biológicos. $3^{\text {a }}$ ed. Viçosa: Universidade Federal de Viçosa; 2002. Português.

4. Lacerda MJR, Freitas KR, da Silva JW. Determinação da matéria seca de forrageiras pelos métodos de microondas e convencional. Bioscience Journal. 2009 Jun [citado 2016 Dez 18]; 25(3):185-190. Português.

5. Ramsumair A, Mlambo V, Lallo CH. Effect of drying method on the chemical composition of leaves from four tropical tree species. Tropical Agriculture (Trinidad). 2014;91(3):179-186. Inglês.

6. Pereira da Silva AL, de Mello Prado R, Silvério da Silva G, Saraiva Bianco M, Alexandre Pancelli M. Influência dos métodos de secagem de amostras de folhas de capim braquiária, cana-de-açúcar e goiabeira nos teores de macronutrientes. Colloquium Agrariae. 2011;7(2):35-40._Português.

7. Calixto Jr M, Jobim CC, Cecato U, Santos GT, Bumbieris Junior VH. Curva de desidratação e composição químico-bromatológica do feno de grama-estrela (Cynodon nlemfuensis Vanderyst) em função do teor de umidade no enfardamento. Semina: Ciências Agrárias [Internet]. 2012 Jul/Set [citado 2016 Dez 20]; 33(6):2411-2422. Disponível em: http://www.redalyc.org/pdf/4457/445744116033.pdf. Português.

8. Godinho RF, Carvalho RCR, Ferreira EA. Determinação de matéria seca em alimentos para uso animal por meio do forno microondas e Koster Tester. Revista de Ciências Agroveterinárias [Internet]. 2014 [citado 2016 Dez 18]; 13(3):293-301. Disponível em: http://revistas.bvs-vet.org.br/rca/article/view/33271/37083. Português.

9. Sarmento HGdS, de Souza David AMS, Barbosa MG, Nobre DAC, Amaro HTR. Determinação do teor de água em sementes de milho, feijão e pinhão-manso por métodos alternativos. Energia na Agricultura [Internet]. 2015 Jul/Set [citado 2016 Dez 20]; 30(3):249-256. http://dx.doi.org/10.17224/EnergAgric.2015v30n3p250256. Português.

10. Natsir A, Egan A, Leury B. Effects of microwave radiation on physico-chemical properties and in vitro digestibility of barley straw. ASAP Conference Proceedings. 2002 [citado 2016 Dez 20]; 24:153-156. Inglês.

11. AOAC - Association of Official Analytical Chemists. Official Methods of Analysis. $15^{\text {th }}$ ed. Vol.1, Agricultural Chemical; Contaminants; Drugs. Arlington: AOAC Inc.; 1990 [citado 2016 Dez 20]. 768 p. https://law.resource.org/pub/us/cfr/ibr/002/aoac.methods.1.1990.pdf. Inglês.

12. Van Soest PJ, Robertson J, Lewis BA. Methods for dietary fiber, neutral detergent fiber, and nonstarch polysaccharides in relation to animal nutrition. Journal of Dairy Science [Internet]. 1991 Out [citado 2016 Dez 29]; 74(10):3583-3597. http://dx.doi.org/10.3168/jds.S0022-0302(91)78551-2. Inglês.

13. SAS Institute. Statistical Analysis System: user guide [CD-ROM]. Version 8. Cary: SAS Insitute Inc., 2002 [citado 2016 Dez 29]. Inglês.

14. Barboza A, Cruz C, Graziani MB, Lorenzetti MC, Sabadini E. Aquecimento em forno de microondas/desenvolvimento de alguns conceitos fundamentais. Química Nova [Internet]. 2001 [citado 2016 
Dez 29]; 24(6): 901-904. http://dx.doi.org/10.1590/S0100-40422001000600030. Português.

15. Cattaneo S, Hidalgo A, Masotti F, Stuknyte M, Brandolini A, De Noni I. Heat damage and in vitro starch digestibility of puffed wheat kernels. Food chemistry [Internet]. 2015 [citado 2016 Dez 29]; 188(1):286-293. http://dx.doi.org/10.1016/j.foodchem.2015.05.019. Inglês.

16. Coblentz WK, Hoffman PC. Heat damaged forages: Effects on forage quality. Focus on Forage [Internet]. 2008 [citado 2016 Dez 29]; 10(8):1-4. Disponível em: http://fyi.uwex.edu/forage/files/2014/01/HeatDamageFOF.pdf. Inglês.

17. Pelletier S, Tremblay GF, Bertrand A, Bélanger G, Castonguay Y, Michaud R. Drying procedures affect non-structural carbohydrates and other nutritive value attributes in forage samples. Animal Feed Science and Technology [Internet]. 2010 Maio [citado $2016 \quad$ Dez 29]; 157(3-4):139-150. https://doi.org/10.1016/j.anifeedsci.2010.02.010. Inglês.

18. Esmelindro MC, Toniazzo G, Waczuk A, Dariva C, Oliveira D. Caracterização físico-química da ervamate: influência das etapas do processamento industrial. Ciência e Tecnologia de Alimentos [Internet]. 2002 Mai/Ago [citado 2016 Dez 29]; 22(2):193-204. http://dx.doi.org/10.1590/S0101-20612002000200016. Português.

19. Serafim RS, Antonelli A, Santos MAT. Determinação da matéria seca e proteína bruta pelo método convencional e microondas. FAZU em Revista [Internet]. 2017 [citado 2016 Dez 29]; 11:39-43. Disponível em: http://www.fazu.br/ojs/index.php/fazuemrevista/article/view/369/472. Português.

20. Marcante NC, Prado RM, Silva M, Rosset JS, Ecco M, Savan PAL. Determinação da matéria seca e teores de macronutrientes em folhas de frutíferas usando diferentes métodos de secagem. Ciência Rural [Internet]. 2010 Dez [citado 2016 Dez 29]; 40(11):2398-2401. http://dx.doi.org/10.1590/S0103-84782010001100025. Português. 